\title{
Evaluasi Kinerja Apill (Alat Pemberi Isyarat Lalu Lintas) Di Kota Semarang (Studi Kasus Di Jalan Dr. Cipto Semarang Sepanjang 2,8 Km Saat Jam Puncak Keramaian)
}

\author{
Radityo Oktianto Pratomo ${ }^{1}$, Rio Adi Pratama ${ }^{1}$, Djoko Setijowarno ${ }^{2}$ \\ email: ${ }^{1}$ radityopratomo95@gmail.com, ${ }^{2}$ rioadipratama14@gmail.com \\ ${ }^{1}$ Mahasiswa Program Studi Teknik Sipil, Fakultas Teknik, Universitas Katolik Soegijapranata, Jl. \\ Pawiyatan Luhur IV/1, Bendan Dhuwur, Semarang 50234 \\ ${ }^{2}$ Dosen Program Studi Teknik Sipil, Fakultas Teknik, Universitas Katolik Soegijapranata, Jl. \\ Pawiyatan Luhur IV/1, Bendan Dhuwur, Semarang 50234
}

\begin{abstract}
Abstrak
Kebutuhan akan transportasi di tiap waktunya, selalu mengalami peningkatan. Namun tingginya akan kebuthan transportasi, tidak di imbangi dengan kapasitas jalan dan pengaturan lalu lintas yang baik. Dalam hal ini, muncul usulan untuk menggunakan suatu sistem bernama Area Traffic Control System (ATCS). Area Traffic Control System (ATCS) adalah suatu system pengendalian simpang lalu lintas jalan raya dengan menggunakan lampu APILL (Alat Pemberi Isyarat Lalu Lintas) dimana pengaturan lampu lalu lintas pada masing-masing simpang saling terkoordinasi, sehingga pengguna jalan mendapatkan tundaan dan panjang antrian yang minimum. Pemerintah Kota Semarang sudah memasang APILL (Alat Pemberi Isyarat Lalu Lintas) di setiap kaki simpang sepanjang jalan DR Cipto, kurangnya APILL (Alat Pemberi Isyarat Lalu Lintas) yang terkoordinasi dengan baik. Membuat panjang antrian di sepanjang jalan DR Cipto semakin tinggi. Metode yang digunakan dalam studi penerapan ini adalah metode survey, antara lain survey volume lalu lintas, panjang antrian, tundaan, dan fase lampu. Hasil survey kemudian diolah dengan menggunakan rumus dari Manual Kapasitas Jalan Indonesia (MKJI). Hasil dari studi penerapan ini adalah didapatkan alternatif koordinasi dengan waktu siklus 68 detik untuk tiap simpangnya. Dan penurunan panjang antrian sepanjang 24,065 m. Seiring berjalannya waktu, jumlah kendaraan akan terus bertambah sedngkan kapasitas jalan tidak mungkin lagi untuk ditambah dan perubahan geometrik pun sulit untuk dilakukan, maka dari itu perlu kebijakan serius dan tegas dari pemerintah untuk menekan pertambahan jumlah kendaraan.
\end{abstract}

Kata kunci : ATCS, Alat Pemberi Isyarat Lalu Lintas, MKJI.

\begin{abstract}
The need for transportation in every time, always increasing. But the high demand for transportation is not matched by road capacity and good traffic management. In this case, a proposal arises to use a system called the Area Traffic Control System (ATCS). Area Traffic Control System (ATCS) is a highway traffic junction control system using APILL lights (Traffic Signal Signs) where the traffic light settings at each intersection are coordinated with each other, so that road users get the delay and minimum queue length. The Semarang City Government has installed a Traffic Sign Giving Tool (APILL) on each foot of the intersection along the DR Cipto road, the lack of a coordinated APILL (Traffic Sign Giving Tool). Making the length of the queue along the DR Cipto road even higher. The method used in the study of this application is a survey method, including survey of traffic volume, queue length, delay, and the phase of the lights. The survey results are then processed using the formula from the Indonesian Road Capacity Manual (MKJI). The results of this implementation study
\end{abstract}


are obtained an alternative coordination with a 68 second cycle time for each intersection. And decrease in queue length along 24,065 m. Over time, the number of vehicles will continue to grow, while road capacity is no longer possible to be added and geometric changes are difficult to do, therefore serious and strict policies from the government are needed to reduce the number of vehicles.

Keywords: ATCS, Traffic Signaling Tool, MKJI.

\section{PENDAHULUAN}

\subsection{Latar Belakang}

Jalan merupakan landasan utama yang digunakan pengguna transportasi untuk melakukan perpindahan dari titik awal hingga titik akhir. Seiring berjalan waktu, pengguna transportasi pada suatu jalan akan mengalami peningkatan. Jika terjadi hal seperti itu tentunya akan mengakibatkan kurangnya kapasitas jalan untuk menampung arus lalu lintas dari pengguna transportasi tersebut, atau dengan nama lain yaitu kemacetan

Pengaturan APILL dengan baik akan membuat koordinasi di tiap kaki simpang berlangsung baik. Namun sebaliknya, pengaturan APILL yang tidak baik, akan membuat koordinasi di setiap kaki simpang berlangsung tidak baik atau dengan nama lain, menimbulkan kemacetan lalu lintas. Sulitnya Dalam hal ini, muncul usulan untuk menggunakan suatu sistem bernama Area Traffic Control System (ATCS).

Menurut Wishnukoro (Sunyoto, 2018) Area Traffic Control System (ATCS) adalah suatu sistem pengendalian simpang lalu lintas jalan raya dengan menggunakan lampu lalu lintas (traffic light) dimana pengaturan siklus waktu dari lampu lalu lintas dapat saling terkoordinasi dengan baik, sehingga pengguna jalan mendapatkan tundaan yang minimum.

Dengan diterapkanya ATCS, penentuan waktu siklus lampu persimpangan dapat diubah berkali-kali dalam satu hari sesuai kebutuhan lalu lintas paling efisien yang mencakup keseluruhan wilayah tersebut.

\subsection{Rumusan Masalah}

APILL (Alat Pemberi Isyarat Lalu Lintas) di Jalan Dr. Cipto Semarang didapati tidak terkoordinir dengan baik antara satu dengan yang lain. Akibat APILL (Alat Pemberi Isyarat Lalu Lintas) yang tidak terkoordinir dengan baik ini menyebabkan di Jalan Dr. Cipto sering mengalami penundaan volume kendaraan yang berujung pada kemacetan lalu lintas di wilayah tersebut. Maka dari itu perlu dipasang alat pengontrol lalu lintas atau sering disebut dengan ATCS (Area Traffic Control System). Alat ini memiliki fungsi untuk mengawasi volume tundaan yang ada sehingga resiko kemacetan dapat berkurang.

Tujuan dari studi penerapan ini adalah sebagai berikut :

1. Untuk mengukur kinerja eksiting berdasarkan standar yang berlaku (MKJI) tahun 1997 dengan studi kasus jalan dr cipto

2. Membuat simulasi di simpang yang sedang diteliti, menggunakan vissim, untuk pengaturan yang lebih baik.

\subsection{Manfaat Penelitian}

Manfaat studi penerapan ini adalah sebagai berikut :

Penelitian ini dapat digunakan sebagai salah satu masukan bagi Pemerintah Kota Semarang dalam hal ini yaitu Dinas Perhubungan Kota Semarang sebagai rancangan dan rujukan kepada pihak 
terkait agar lalu lintas di Jalan Dr. Cipto Semarang menjadi lebih efesien seperti mengurangi panjang antrian akibat APILL (Alat Pemberi Isyarat Lalu Lintas) yang tidak tersinkronisasi dari satu simpang ke simpang lainnya.

\section{TINJAUAN PUSTAKA}

\subsection{Lalu Lintas}

Lalu lintas jalan adalah prasarana yang diperuntukkan untuk kendaraan, orang, atau barang yang melakukan gerak dan perpindahan. Berupa jalan sebagai fasilitas pendukung. Untuk mengendalikan pergerakan orang dan atau kendaraan agar bisa berjalan dengan lancar dan aman diperlukan APPILL (Alat Pemberi Isyarat Lalu Lintas). Kegunaan APILL pada kondiso arus lalu lintas yaitu mempertahankan kapasitas sinpang pada jam keramaian. Dan mengurangi kecelakaan lalulintas akibat arah jalan yang berlawanan. (Kementrian Pekerjaan Umum, 2014.) Kemacetan merupakan salah satu penyebab terjadinya permasalahan lalulintas. Yaitu meningkatnya volume kendaraan roda 2 dan roda 4 , maka dari itu perlu adanya manajemen lalulintas, agar kemacetan tidak terjadi semakin parah.

\subsection{Manajemen Lalu Lintas}

Tujuan pokok manajemen lalu lintas adalah memaksimumkan pemakaian sistem jalan yang ada dan meningkatkan keamanan jalan, tanpa merusak kualitas lingkungan.

\subsection{Persimpangan}

Persimpangan adalah lokasi yang berpotesi penyebab terjadinya tundaan serta masalah lalu lintas lainya, dikarenakan terhimpunya titik konflik pengguna transportasi dalam satu lokasi.
(Meditra, 2010). Dan persimpangan merupakan pertemuan jalan yang bercabang dari sebidang maupun tidak sebidang. (Direktur Jendreal Perhubungan Barat, 1996).

Masalah yang saling terkait pada persimpangan adalah:

a. Volume dan kapasitas ang secara langsng mempengaruhi hambatan

b. Desain geometrik dan kebebasan samping

c. Kecelakaan dan keselamatan jalan, kecepatan, lampu jalan

d. Parkir, akses dan pembangunan yang sifatnya umum

e. Pejalan kaki

f. Jarak antar persimpangan

\subsection{Simpang Bersinyal}

Simpang bersinyal adalah simpang yang dikendalikan oleh sinyal. Sinyal adalah semua peralatan pengatur yang menggunakan tenaga listrik, rambu dan marka jalan untuk mengarahkan atau memperingatkan pengemudi kendaraan bermotor, pengendara sepeda, atau pejalan kaki. Penggunaan sinyal dengan lampu tiga warna pada traffic light (merah, kuning, hijau) dilakukan untuk dapat memisahkan lintasan dari gerakangerakan lalu lintas yang saling bertentangan dalam dimensi waktu yang terjadi bersamaan. Konflik-konflik gerakan lalu lintas di persimpangan bersinyal dapat dibagi menjadi dua, yaitu konflik-konflik utama dan konflik-konflik kedua.

\subsection{Menghitung Kinerja Lalu Lintas Simpang APILL}

\subsubsection{Panjang Antrian}

Menurut Pedoman Kapasitas Jalan Indonesia 2014, Jumlah rata-rata antrian kendaraan (skr) pada awal isyarat lampu 
hijau $\left(\mathrm{N}_{\mathrm{Q}}\right)$ dihitung sebagi jumlah kendaraan terhenti (skr) yang tersisa dari fase hijau sebelumnya $\left(\mathrm{N}_{\mathrm{Q} 1}\right)$ ditambah jumlah kendaraan (skr) yang datang dan terhenti dalam antrian selama fase merah $\left(\mathrm{N}_{\mathrm{Q} 2}\right)$, dihitung menggunakan rumus.

$\mathrm{N}_{\mathrm{Q}}=\mathrm{N}_{\mathrm{Q} 1}+\mathrm{N}_{\mathrm{Q} 2}$

Jika nilai $D_{\mathrm{J}}>0,5$, maka nilai

$\mathrm{N}_{\mathrm{Q} 1}=0.25 \times \mathrm{c} \times\left\{\left(D_{J}-1\right)^{2}+\right.$

$\left.\sqrt{\left(D_{J}-1\right)^{2}+\frac{8 \times\left(\mathrm{D}_{J}-0.5\right)}{\mathrm{c}}}\right\}$

Apabila diketahui derajat kejenuhan DJ

$\leq 0,5$, maka nilai $\mathrm{NQ} 1=0$

$\mathrm{N}_{\mathrm{Q} 2}=\mathrm{c} \times \frac{\left(1-R_{H}\right)}{\left(1-R_{H} \times D_{J}\right)} \times \frac{\mathrm{Q}}{3600}$.

Setelah itu, panjang antrian (PA) diperoleh dari hasil perkalian $\mathrm{N}_{\mathrm{Q}}(\mathrm{skr})$ dengan luas area rata-rata yang digunakan oleh satu kendaraan ringan (ekr) yaitu $20 \mathrm{~m}^{2}$, dibagi lebar masuk (m) seperti pada rumus berikut :

$\mathrm{PA}=\mathrm{N}_{\mathrm{Q}} \times \frac{20}{\mathrm{~L}_{\mathrm{M}}}$

\subsubsection{Rasio Kendaraan Terhenti}

Rasio kendaraan terhenti (RKH) merupakan rasio kendaraan pada pendekat yang harus terhenti akibat isyarat merah sebelum melewati suatu simpang terhadap jumlah arus pada fase yang sama pada pendekat tersebut dihitung menggunakan rumus.

$\mathrm{R}_{\mathrm{KH}}=0.9 \times \frac{\mathrm{N}_{\mathrm{Q}}}{\mathrm{Q} x c} \times 3600$.

Keterangan :

$\mathrm{N}_{\mathrm{Q}}=$ jumlah rata-rata antrian kendaraan (skr) pada awal isyarat hijau

$c=$ waktu siklus (detik)

$\mathrm{Q}=$ arus lalu lintas dari pendekat yang ditinjau (skr/jam)
Jumlah rata-rata kendaraan berhenti $\left(\mathrm{N}_{\mathrm{H}}\right)$ adalah jumlah berhenti rata-rata per kendaraan (termasuk berhenti ulang dalam antrian) sebelum melewati suatu simpang yang dihitung menggunakan rumus

$\mathrm{N}_{\mathrm{H}}=\mathrm{Q} \times \mathrm{R}_{\mathrm{KH}}$

\subsubsection{Tundaan}

Tundaan merupakan waktu tempuh tambahan yang diperlukan pengendara untuk melewati suatu simpang dibandingkan terhadap situasi tanpa simpang. Tundaan simpang terjadi karena dua hal yaitu tundaan lalu lintas dan tundaan geometrik. Tundaan lalu lintas rata-rata dihitung dengan rumus PKJI 2014 yaitu sebagai berikut :

$\mathrm{Ti}=\mathrm{Tli}+\mathrm{Tgi}$

Tundaan lalu lintas rata-rata (TL) pada suatu pendekat dapat dihitung dengan rumus 2-18.

$\mathrm{T}_{\mathrm{L}}=c \times \frac{0,5 \times\left(1-R_{H}\right)^{2}}{\left(1-R_{H} \times D_{J}\right.}+\frac{N_{Q 1}}{C} \times 3600 .$.

Tundaan Geometrik (TG) yaitu tundaan yang disebabkan oleh perlambatan dan percepatan untuk melewati suatu fasilitas (misal akibat lengkung horisontal pada suatu persimpangan atau terhenti karena lampu merah). Tundaan geometri dapat dihitung dari rumus.

$\mathrm{TG}=\left(1-\mathrm{R}_{\mathrm{KH}}\right) \times \mathrm{P}_{\mathrm{B}} \times 6+\left(\mathrm{R}_{\mathrm{KH}} \times 4\right)$.

Keterangan :

$\mathrm{P}_{\mathrm{B}}=$ porsi kendaraan membelok pada suatu pendekat

\subsubsection{Data kondisi arus lalu lintas}

Data arus lalu lintas meliputi:

1. Arus lalu lintas per jenis kendaraan bermotor dan tak bermotor (qKR, qKB, qSM, qKTB) dengan distribusi gerakan LRS, BKa, dan BKi. Tuliskan data arus ini pada masingmasing pendekat (U,S,T,B) ataupun sub-pendekat (U1,U2,dst.). 
2. Konversikan arus kedalam satuan skr/jam. Gunakan nilai ekr pada Tabel B.2. Lampiran B.

3. Rasio arus kendaraan belok kiri (RBKi) dan rasio arus belok kanan (RBKa) untuk masingmasing pendekat.

$\mathrm{R}_{\mathrm{BKi}}=\frac{Q_{B K i}}{Q_{\text {Total }}}$.

$\mathrm{R}_{\mathrm{BKi}}=\frac{Q_{B K a}}{Q_{\text {Total }}}$

4. Rasio kendaraan tak bermotor (RKTB) untuk masing-masing pendekat.

$\mathrm{R}_{\mathrm{BKi}}=$

$\frac{Q_{K T B}}{Q_{K T B}+Q_{K B T}}$

2.6 Alat Pemberi Isyarat Lalu Lintas (APILL)

Menurut

(Departemen

perhubungan direktorat jenderal perhubungan darat 1996) Alat Pemberi Isyarat Lalu Lintas (APILL). Memiliki 3 warna yaitu merah, kuning, hijau. Berikut merupakan penjelasan dari warna yang terdapat di Alat Pemberi Isyarat Lalu Lintas (APILL):

1. Lampu tiga warna untuk mengatur kendaraan, susunan lampu tiga warna adalah cahaya berwarna merah, kuning dan hijau.

2. Lampu dua warna, untuk mengatur kendaraan dan pejalan kaki. Susunan lampu dua warna adalah cahaya berwarna merah dan hijau.

3. Lampu satu warna untuk memberikan peringatan bahaya kepada pemakai jalan. lampu itu berwarna kuning atau merah.

Seperti yang harus diketahui, Alat Pemberi Isyarat Lalu Lintas (APILL). Memiliki tujuan, agar dalam pemasanganya memiliki dampak positif, bagi pengguna jalan. berikut merupakan tujuan dari Alat Pemberi Isyarat Lalu Lintas ( APILL) : a. Menghindari hambatan karena adanya perbedaan arus jalan bagi pergerakan kendaraan..

b. Memfasilitasi pejalan kaki untuk menyebrang, yaitu zebra cross. Yang dapat digunakan saat pergerakan pengendara berhenti saat fase lampu merah.

c. Menghindari tingkat kecelakaan lalu lintas, yang disebabkan karena perbedaan perbedaan arus jalan.

\subsection{Area Traffic Control System (ATCS)}

Menurut Wishnukoro (Sunyoto, 2018), Area Traffic Control System (ATCS) adalah suatu sistem pengendalian simpang lalu lintas jalan raya dengan menggunakan lampu lalu lintas (traffic light) dimana pengaturan lampu lalu lintas pada masingmasing simpang saling terkoordinasi, sehingga pengguna jalan mendapatkan tundaan yang minimum. Dengan penerapan ATCS atau lampu lalu lintas terkoordinasi maka akan terjadi efisiensi pergerakan dan akan meningkatkan kapasitas simpang untuk melayani lalu lintas, waktu perjalanan yang lebih pendek, penurunan tingkat resiko kecelakaan bagi pengendara dan kesempatan juga keselamatan yang lebih tinggi bagi pejalan kaki/penyeberang jalan serta kenyamanan pengguna jalan yang lebih baik. ATCS baik diterapkan untuk simpang yang memiliki sitik konflik arus lalu lintas yang cukup tinggi. Berikut manfaat dari Area Traffic Control System (ATCS)

a. Mengurangi resiko kecelakaan lalu lintas

b. Penggunaan bahan bakar yang lebih hemat, dikarenakan berkurangnya waktu perjalanan

c. Mengurangi polusi udara dan suara kendaraan 
d. Memberi kelancaran bagi kendaraan penting yang akan melewati arus jalan tersebut. Seperti contoh ambulance dan pemadam kebarakan

Dalam penerapan Area Traffic Control System (ATCS). Perlu pengoprasian, agar manfaat dari ATCS dapat berdapak baik kepada pengguna lalulintas. Berikut merupakan komponen dalam pengoprasiap Area Traffic Control system (ATCS).

a. Pengatur arus persimpangan berupa lampu lalu lintas (APILL)

b. Penginput data lalulintas berupa kamera CCTV pemantau.

c. Pengirim data berupa jaringan kabel data atau pemancar gelombang

d. Central room control atau ruang control plus operatornya.

\subsection{Sofware VISSIM Version 9.00-03 (Student)}

Pada pemodelan Lalu Lintas menggunakan Aplikasi yang digunakan dalam mengolah data Lalu Lintas yaitu Program software VISSIM 9.00-03 (Student). Adapun pengertian dari VISSIM 9.00-03 (Student) VISSIM dimulai pada tahun 1992 dan saat ini menjadi pemimpin pasar global. VISSIM model simulasi telah dipilih untuk mengkalibrasi kondisi jalan Simpang (Intresection). Terjadinya konflik di persimpangan merupakan hal yang biasa dalam kehidupan sehari-hari, maka dari itu dibutuhkan pengendalian persimpangan guna mengurangi konflik yang ada di persimpangaan. Variabel Penentu Kinerja Simpang Variabel penentu kinerja simpang pada Lalu Lintas menyatakan bahwa ukuran kuantitas yang mengambarkan kondisi keadaan Lalu Lintas yang di dapat oleh pembuatan jalan yang kurang signifikan. Perilaku pada simpang bersinyal antara lain yaitu:
a. Kapasitas,
b. Panjang antrian,
c. Rasio kendaraan henti,
d. Tundaan,
e. Derajat kejenuhan,
f. Waktu siklus,
g. Arus dan kecepatan.

\section{METODE PENELITIAN}

\subsection{Lokasi Penelitian}

Lokasi yang menjadi studi kasus pada penelitian ini adalah jalan dr cipto Kota Semarang Provinsi Jawa Tengah. Penilitian ini dimulai dari jalan dr cipto hingga ke jalan dr cipto dengan jarak kurang lebih $1,3 \mathrm{~km}$. Penelitian ini dilakukan agar pemasangan ATCS di lokasi tersebut perlu ditinjau dari kinerjanya, supaya waktu tundaan dan panjang antrian di persimpangan tersebut tidak berlangsung lama. Untuk mewujudkan koordinasi persimpangan dengan tundaan yang singkat, perlu dilakukan rekayasa durasi APILL dan mengoptimalisasi pengoperasian ATCS di persimpangan di jalan dr cipto.

\subsection{Pengumpulan Data}

Data - data yang diperlukan dalam penelitian ini berasal dari beberapa survei diantaranya data sekunder yaitu berupa data dari instansi seperti data penduduk Kota Semarang dan tundaan lampu lalu lintas, serta data primer yang meliputi data volume lalu lintas, tundaan, panjang antrian, dan fase lampu lalu lintas yang didapat dari survei di lapangan. Survei di lapangan dilakukan pada hari Senin, Rabu, Jumat, Sabtu dan disaat tidak ada event, dikarenakan pada hari tersebut sangat efektif untuk dilakukannya survey.

\subsection{Pengambilan Data Primer}

a) Survei Volume Lalu Lintas 
Survei volume Lalu Lintas dilakukan dengan cara mencatat satu - persatu setiap kendaraan yang lewat dengan periode waktu catatnya dibagi 15 menit sekali, dalam kurun waktu 2 jam dalam sehari.

b) Survei Tundaan dan Panjang Antrian Untuk survei tundaan ini diperlukan surveyor minimal dua orang (tergantung volume lalu lintas ). Orang pertama bertugas menghitung jumlah kendaraan yang antri atau menunggu pada saat lampu merah tiap 20 detik sedangkan orang kedua bertugas menghitung jumlah kendaraan yang keluar simpang pada saat lampu hijau yang diklasifikasi menjadi dua jenis, yaitu kendaraan yang berhenti dan kendaraan yang tidak berhenti.

c) Survei Arus Jenuh

Survei ini dilakukan dengan cara mencatat kendaraan yang berhenti terakhir pada setiap kelompok mobil yang datang pada saat lampu APILL nenunjukkan warna merah.

d) Survei Waktu Siklus

Survei ini dilakukan dengan cara mencatat waktu lampu nyala merah, hijau, kuning dengan menggunakan stopwatch pada setiap lengan simpang, dilakukan berulang selama 5 siklus

e) Survei Kendaraan Henti

Survei tundaan ini dilakukan dengan cara menghitung sisa kendaraan henti pada saat perubahan lampu hijau ke merah.

Untuk waktu survei di atas dilakukan pada hari Senin, Kamis dan Sabtu. Untuk waktu survei pada hari tersebut dilakukan pada jam 06.00-07.00 WIB dan 17.00-18.00 WIB.

\subsection{Pengambilan Data sekunder}

Data sekunder didapat dari instansi pemerintahan terkait, seperti data jumlah penduduk kota. Data penduduk dibutuhkan untuk menentukan faktor ukuran kota serta pengaruhnya terhadap kemacetan di Kota Semarang.

\subsection{Hasil Penelitian}

Hasil dari penelitian ini berdasarkan pada teori yang ada dan relevan, dan dilakukan secara intensif dan dikontrol dalam pelaksanaannya. Hasil dari penelitian ini akan dibandingkan dengan standart teori yang berada di buku panduan. Dengan begitu, maka akan terlihat keberhasilan pemasangan ATCS di persimpangan tersebut.

\section{HASIL PENELITIAN DAN PEMBAHASAN \\ 4.1 Hasil Penelitian}

Hasil dalam penelitian ini merupakan hasil dari metode survey yang telah dilakukan. Survey yang telah dilakukan meliputi survey volume lalu lintas, survey panjang antrian, dan survey faske lampu. Survey dilakukan selama 3 minggu. Pada hari Senin, Kamis dan sabtu. pada jam 06.00-07.00 WIB untuuk jam pagi dan 17.00-18.00 WIB untuk waktu sore. Pemilihan waktu ditentukan oleh waktu sibuk, kondisi hari, dan tidak adanya kegiatan event pada hari tersebut.

\subsection{Analisis dan Pembahasan}

Dengan menggunakan data pada tabel Sub bab 4.1. maka dilakukan perhitungan dengan menggunakan rumus :

$\mathrm{Q}=\mathrm{Q}_{\mathrm{Lv}}+\mathrm{Q}_{\mathrm{Hv}} \times \mathrm{emp}_{\mathrm{lv}}+\mathrm{Q}_{\mathrm{SM}} \times \mathrm{emp}_{\mathrm{SM}}$

Dapat dilihat pada gambar grafik berikut total $\mathrm{Q}$ arus lalu lintas yang memiliki kepadatan tinggi adalah hari sabtu yaitu dengan data simpang Titik 0 (931,5 smp) , Simpang Kartini (1103,3 smp), Simpang Sidodadi (775,7 smp), 
Simpang Majapahit (1340 smp).

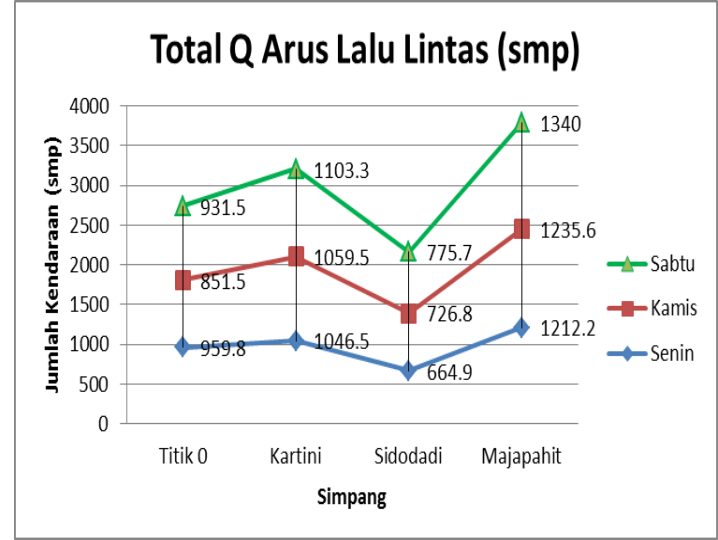

Berdasarkan perhitungan menggunakan rumus MKJI, dihasilkan waktu hijau pada masing-masing simpang untuk hari Senin, Kamis dan Sabtu. Sedangkan untuk kondisi dilapangan waktu siklus hijau dari simpang titik 0 dengan kakii simpang yang mengarah ke jalan DR. Cipto Semarang. Jalan karang ndoro dan patimura 25 detik. Simpang kartini dengan kaki simpang yang mengarah ke jalan Dr Cipto Semarang. Jalan Dr Cipto (1) 30 detik, pasar bururng 15 detik, pasar langgar 22 detik. Simpang sidodadi dengan kaki simpang yang mengarah ke jalan DR. Cipto Semarang. Jalan Dr Cipto (2) 24 detik dan Sidodadi timur 10 detik. Simpang Majapahit dengan kaki simpang yang keluar dr arah Dr Cipto Semarang. Jalan Dr Cipto (3) 26 detik Dengan hasil yang sudah di sebutkan diatas waktu hijau di lapangan sendiri memiliki fase lampu hijau yang lebih banyak daripada perhitungan MKJI sehingga dapat disimpulkan bahwa fase lampu di kedua simpang masih baik.
Lalu dapat diilakukan perhitungan Derajat Kejenuhan dengan menggunakan rumus $D j=\frac{Q}{c}$. Hasil dari perhitungan derajat kejenuhan pada tiap kaki simpang.

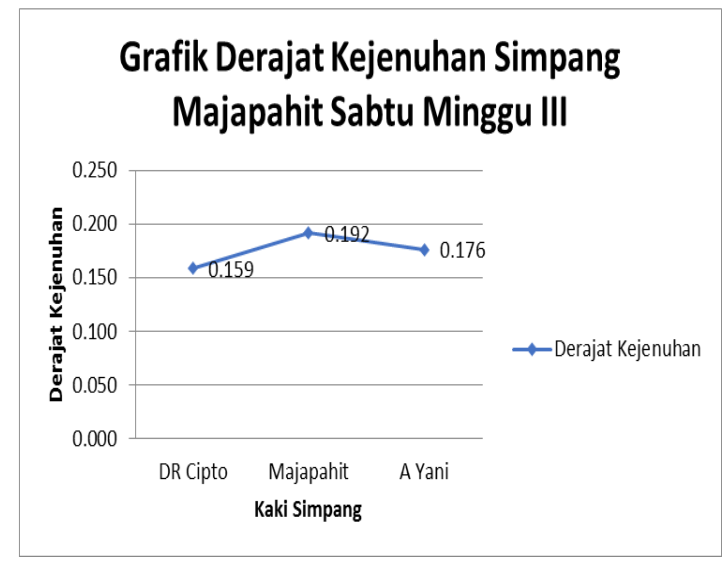

Dari hasil grafik di atas memperlihatkan perbandingan derajat kejenuhan pada tiap kaki simpang baik. Jika derajat kejenuhan mencapai angka di atas 0,85 maka diperlukan sebuah perencanaan kembali untuk kaki simpang tersebut. Perencanaan kembali tersebut dapat meliputi perubahan fase dan isyarat lampu ataupun melakukan pelebaran jalan masuk pada kaki simpang tersebut.

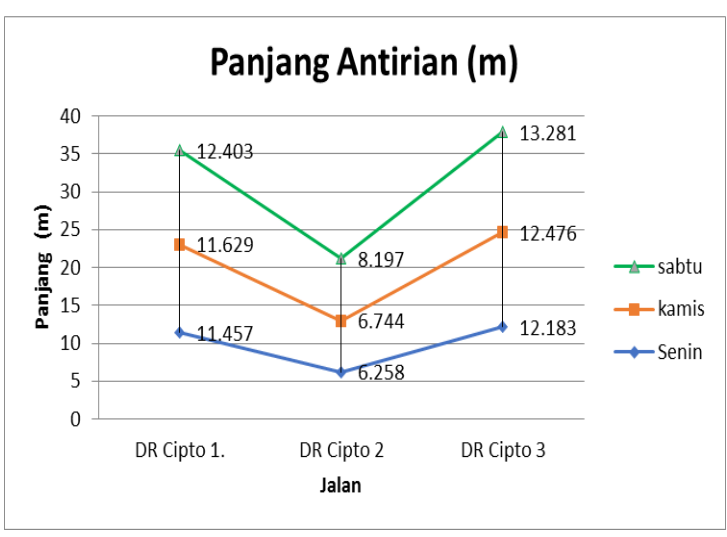

Dapat dilihat pada gambar grafik di atas, panjang antrian tertinggi terjadi pada jalan Dr Cipto 3 di simpang majapahit. 
Pada hari senin 12,183 meter, Kamis 12,476 meter, Sabtu 13,281 meter. Dari data tersebut bisa disimpulkan bahwa panjang antrian cukup tinggi terjadi di jalan Dr Cipto 3 di simpang majapahit. Hari Senin, Kamis dan Sabtu pada minggu ke III. Oleh sebab itu dibutuhkan koordinasi APIL (Alat Pemberi Isyarat Lalu Lintas) yang baik agar, meminimalisir panjang antrian yang cukup tinggi. Dan untuk Tundaan Geometrik (Tg) dapat dikatan normal karena tidak melebihi angka 6 yang merupakan batas maksimal angka tundaan geometrik menurut MKJI 1997.

\subsection{Koordinasi dan Simulasi}

Berdasarkan perhitungan maka dapat dihasilkan 3 simulasi perhitungan untuk dapat menentukan koordinasi antar 2 Simpang.

\begin{tabular}{|c|c|c|c|c|c|c|c|c|c|c|}
\hline \multirow{2}{*}{ Simpang } & \multirow{2}{*}{ Pendekat } & \multicolumn{4}{|c|}{ WaktuSiklss } & \multirow{2}{*}{ Total } & \multirow{2}{*}{\begin{tabular}{|c|} 
PA \\
meter \\
\end{tabular}} & \multirow{2}{*}{\begin{tabular}{|l|} 
Tundaan \\
detssmp \\
\end{tabular}} & \multirow{2}{*}{$\begin{array}{c}\text { Derajat } \\
\text { Kejemulan }\end{array}$} & \multirow{2}{*}{ Keterangan } \\
\hline & & Allind & Merah & \begin{tabular}{|l|} 
Kuning \\
\end{tabular} & Hijau & & & & & \\
\hline \multirow{3}{*}{ titik 0} & $\begin{array}{l}\text { KARANG } \\
\text { NDORO }\end{array}$ & 3 & 24 & 2 & 18 & \multirow{3}{*}{65} & 9.989 & 10.660 & 0.171 & BAIK \\
\hline & CITARUM & 3 & 40 & 2 & 10 & & 9.962 & 10.896 & 0.170 & BAIK \\
\hline & PATMMURA & 3 & 28 & 2 & 16 & & 10.325 & 11.095 & 0.174 & BAIK \\
\hline \multirow{3}{*}{ Kartini } & DRCIPTO & 3 & 30 & 2 & 15 & \multirow{3}{*}{65} & 10.308 & 11.087 & 0.210 & BAIK \\
\hline & P. BURUNG & 3 & 28 & 2 & 16 & & 25.447 & 11.912 & 0.207 & $\begin{array}{l}\text { TIDAK } \\
\text { BAIK }\end{array}$ \\
\hline & P. LANGGAR & 3 & 24 & 2 & 18 & & 25.013 & 11.759 & 0.199 & $\begin{array}{c}\text { TIDAK } \\
\text { BAIK }\end{array}$ \\
\hline \multirow{3}{*}{ Sidodadi } & DRCIPT0 & 3 & 34 & 2 & 13 & \multirow{3}{*}{65} & 9.800 & 10.311 & 0.166 & BAIK \\
\hline & $\begin{array}{c}\text { SIDODADI } \\
\text { TIMUR }\end{array}$ & 3 & 26 & 2 & 17 & & 22.380 & 11.194 & 0.163 & $\begin{array}{l}\text { TIDAK } \\
\text { BAIK } \\
\end{array}$ \\
\hline & $\begin{array}{c}\text { SIDODADI } \\
\text { BARAT }\end{array}$ & 3 & 24 & 2 & 18 & & 25.506 & 12.515 & 0.199 & $\begin{array}{l}\text { TIDAK } \\
\text { BAIK }\end{array}$ \\
\hline \multirow{3}{*}{ Majapahit } & DRCIPT0 & 3 & 30 & 2 & 15 & \multirow{3}{*}{65} & 11.386 & 12.102 & 0.260 & BAIK \\
\hline & MAJAPAHIT & 3 & 28 & 2 & 16 & & 10.293 & 11.273 & 0.244 & BAIK \\
\hline & AYANI & 3 & 24 & 2 & 18 & & 10.393 & 11.254 & 0.221 & BAIK \\
\hline
\end{tabular}

Sumber : hasil analisis, 2019

\begin{tabular}{|c|c|c|c|c|c|c|c|c|c|c|}
\hline \multirow{2}{*}{ Simpang } & \multirow{2}{*}{ Pendekat } & \multicolumn{4}{|c|}{ Waktu Skiks } & \multirow{2}{*}{ Total } & \multirow{2}{*}{\begin{tabular}{|c|} 
PA \\
meter \\
\end{tabular}} & \multirow{2}{*}{\begin{tabular}{|l|} 
Tuxdana \\
detssmp \\
\end{tabular}} & \multirow{2}{*}{$\begin{array}{c}\text { Derajalt } \\
\text { Kejemulan }\end{array}$} & \multirow{2}{*}{ Keterangan } \\
\hline & & All red & Merah & Kuning & Hijaul & & & & & \\
\hline \multirow{3}{*}{ trikik 0} & $\begin{array}{l}\text { KARANG } \\
\text { NDORO }\end{array}$ & 3 & 35 & 2 & 16 & \multirow{3}{*}{72} & 10.402 & 11.090 & 0.177 & BAIK \\
\hline & CITARLM & 3 & 41 & 2 & 13 & & 12.004 & 128.15 & 0.198 & BAIK \\
\hline & PATIMURA & 3 & 37 & 2 & 15 & & 11.879 & 12.600 & 0.196 & BAIK \\
\hline \multirow{3}{*}{ Kartini } & DRCIPTO & 3 & 31 & 2 & 18 & \multirow{3}{*}{72} & 10.308 & 11.087 & 0.210 & BAIK \\
\hline & P. BIRUNG & 3 & 37 & 2 & 15 & & 25.447 & 11.912 & 0.207 & $\begin{array}{l}\text { TIDAK } \\
\text { BAIK } \\
\end{array}$ \\
\hline & P. LANGGAR & 3 & 39 & 2 & 14 & & 25.013 & 11.759 & 0.199 & $\begin{array}{l}\text { TIDAK } \\
\text { BAIK }\end{array}$ \\
\hline \multirow{3}{*}{ Sidodadi } & DRCIPTO & 3 & 31 & 2 & 18 & \multirow{3}{*}{72} & 10.358 & 10.986 & 0.174 & BAIK \\
\hline & $\begin{array}{c}\text { SIDODADI } \\
\text { TIMUR }\end{array}$ & 3 & 41 & 2 & 13 & & 26.009 & 12.626 & 0.184 & $\begin{array}{l}\text { TIDAK } \\
\text { BAKK }\end{array}$ \\
\hline & $\begin{array}{c}\text { SIDODADI } \\
\text { BARAT }\end{array}$ & 3 & 39 & 2 & 14 & & 26.078 & 12.669 & 0.194 & $\begin{array}{c}\text { TIDAK } \\
\text { BAIK } \\
\end{array}$ \\
\hline \multirow{3}{*}{ Majppahit } & DRCIPTO & 3 & 35 & 2 & 16 & \multirow{3}{*}{72} & 10.690 & 11.476 & 0.247 & BAIK \\
\hline & MAJAPAHTT & 3 & 41 & 2 & 13 & & 12.364 & 13.127 & 0.284 & BAIK \\
\hline & AYANI & 3 & 37 & 2 & 15 & & 11.961 & 12.645 & 0.248 & BAIK \\
\hline
\end{tabular}

Sumber : hasil analisis, 2019

\begin{tabular}{|c|c|c|c|c|c|c|c|c|c|c|}
\hline \multirow{2}{*}{ Simpang } & \multirow{2}{*}{ Pendekat } & \multicolumn{4}{|c|}{ WaktuSkhls } & \multirow{2}{*}{ Total } & \multirow{2}{*}{\begin{tabular}{|c|}
$\mathrm{PA}$ \\
meter \\
\end{tabular}} & \multirow{2}{*}{$\begin{array}{l}\text { Tuxdaan } \\
\text { detsmpp }\end{array}$} & \multirow{2}{*}{$\begin{array}{c}\text { Derajalt } \\
\text { Kejenulan }\end{array}$} & \multirow{2}{*}{ Keterangan } \\
\hline & & All red & Merah & Kuning & Hijau & & & & & \\
\hline \multirow{3}{*}{ titik 0} & KARANG & 3 & 29 & 2 & 17 & \multirow{3}{*}{68} & 9.845 & 10.587 & 0.169 & BAIK \\
\hline & CITARUM & 3 & 33 & 2 & 15 & & 10.354 & 11.354 & 0.176 & BAIK \\
\hline & PATIMURA & 3 & 31 & 2 & 16 & & 11.619 & 12.368 & 0.192 & BAIK \\
\hline \multirow{3}{*}{ Kartini } & DRCIPTO & 3 & 29 & 2 & 17 & \multirow{3}{*}{68} & 9.745 & 10.50 & 0.201 & BAIK \\
\hline & P. BURUNG & 3 & 31 & 2 & 16 & & 21.783 & 10.447 & 0.183 & $\begin{array}{l}\text { TIDAK } \\
\text { BAIK }\end{array}$ \\
\hline & P. LANGGAR & 3 & 33 & 2 & 15 & & 24.436 & 11.529 & 0.196 & $\begin{array}{c}\text { TIDAK } \\
\text { BAIK }\end{array}$ \\
\hline \multirow{3}{*}{ Sidodadi } & DR CIPTO & 3 & 31 & 2 & 16 & \multirow{3}{*}{68} & 9.800 & 10.482 & 0.166 & BAIK \\
\hline & $\begin{array}{c}\text { SIDODADI } \\
\text { TIMUR }\end{array}$ & 3 & 35 & 2 & 14 & & 22.380 & 11.178 & 0.163 & $\begin{array}{l}\text { TIDAK } \\
\text { BAIK }\end{array}$ \\
\hline & $\begin{array}{c}\text { SIDODADI } \\
\text { BARAT }\end{array}$ & 3 & 33 & 2 & 15 & & 25.506 & 12.438 & 0.190 & $\begin{array}{l}\text { TIDAK } \\
\text { BAIK }\end{array}$ \\
\hline \multirow{3}{*}{ Majppait } & DRCIPTO & 3 & 35 & 2 & 14 & \multirow{3}{*}{68} & 10.127 & 10.970 & 0.236 & BAIK \\
\hline & MAJAPAHTT & 3 & 31 & 2 & 16 & & 10.698 & 11.635 & 0.252 & BAIK \\
\hline & AYANI & 3 & 27 & 2 & 18 & & 11.698 & 12.412 & 0.244 & BAIK \\
\hline
\end{tabular}

Sumber : hasil analisis, 2019

\begin{tabular}{|c|c|c|c|c|c|c|c|c|c|c|}
\hline \multirow{2}{*}{ Simpang } & \multirow{2}{*}{ Pendekat } & \multicolumn{4}{|c|}{ WaktuSkklus } & \multirow{2}{*}{ Total } & \multirow{2}{*}{$\frac{P A}{\text { meter }}$} & \multirow{2}{*}{$\begin{array}{l}\text { Tundaan } \\
\text { detsmmp }\end{array}$} & \multirow{2}{*}{$\begin{array}{c}\text { Derajat } \\
\text { Kejenulan }\end{array}$} & \multirow{2}{*}{ Keterangan } \\
\hline & & Allnd & Merah & Kuning & Hijaul & & & & & \\
\hline \multirow{3}{*}{ trikik 0} & $\begin{array}{l}\text { KARANG } \\
\text { NDORO }\end{array}$ & 3 & 33 & 2 & 15 & & 11.092 & 11.712 & 0.186 & BAIK \\
\hline & CITARLM & 3 & 35 & 2 & 14 & & 9.953 & 10.999 & 0.170 & BAIK \\
\hline & PATMURA & 3 & 31 & 2 & 16 & & 10326 & 11.217 & 0.174 & BAIK \\
\hline \multirow{3}{*}{ Kartini } & DRCIPTO & 3 & 33 & 2 & 15 & \multirow{3}{*}{67} & 11.004 & 11.702 & 0.221 & BAIK \\
\hline & P. BIRUNG & 3 & 31 & 2 & 16 & & 20.892 & 10.093 & 0.177 & $\begin{array}{l}\text { TIDAK } \\
\text { BAIK }\end{array}$ \\
\hline & P. LANGGAR & 3 & 29 & 2 & 17 & & 21.565 & 10.389 & 0.178 & $\begin{array}{l}\text { TIDAK } \\
\text { BAIK }\end{array}$ \\
\hline \multirow{3}{*}{ Sidodadi } & DRCIPTO & 3 & 33 & 2 & 15 & \multirow{3}{*}{67} & 11.047 & 11.608 & 0.183 & BAIK \\
\hline & $\begin{array}{c}\text { SIDODADI } \\
\text { TIMUR }\end{array}$ & 3 & 31 & 2 & 16 & & 21.498 & 10.828 & 0.158 & $\begin{array}{l}\text { TIDAK } \\
\text { BAIK }\end{array}$ \\
\hline & $\begin{array}{c}\text { SIDODADI } \\
\text { BARAT }\end{array}$ & 3 & 33 & 2 & 15 & & 22.662 & 11.296 & 0.173 & $\begin{array}{l}\text { TIDAK } \\
\text { BAIK }\end{array}$ \\
\hline \multirow{3}{*}{ Majpapalit } & DRCIPTO & 3 & 29 & 2 & 17 & \multirow{3}{*}{67} & 11.386 & 12.102 & 0.260 & BAIK \\
\hline & MAJAPAHT & 3 & 33 & 2 & 15 & & 10.293 & 11.273 & 0.244 & BAIK \\
\hline & AYANI & 3 & 31 & 2 & 16 & & 10.393 & 11.254 & 0.221 & BAIK \\
\hline
\end{tabular}

Sumber : hasil analisis, 2019 


\begin{tabular}{|c|c|c|c|c|c|c|c|c|c|c|}
\hline \multirow{2}{*}{ Simpang } & \multirow{2}{*}{ Pendekat } & \multicolumn{4}{|c|}{ Waktu Siklis } & \multirow{2}{*}{ Total } & \multirow{2}{*}{$\begin{array}{l}\text { PA } \\
\text { meter } \\
\end{array}$} & \multirow{2}{*}{\begin{tabular}{|l|} 
Tundaan \\
detsmp \\
\end{tabular}} & \multirow{2}{*}{$\begin{array}{c}\text { Derajat } \\
\text { Kejemban }\end{array}$} & \multirow{2}{*}{ Keterangar } \\
\hline & & Allred & Merah & Kuning & Hinau & & & & & \\
\hline \multirow{3}{*}{ titik 0} & $\begin{array}{l}\text { KARANG } \\
\text { NDORO }\end{array}$ & 3 & 31 & 2 & 16 & \multirow{3}{*}{68} & 7.988 & 8.912 & 0.143 & BAIK \\
\hline & CITARUM & 3 & 35 & 2 & 14 & & 7.978 & 9.262 & 0.143 & BAIK \\
\hline & PATIMURA & 3 & 31 & 2 & 16 & & 7.965 & 9.122 & 0.142 & BAIK \\
\hline \multirow{3}{*}{ Kartini } & DRCIPT0 & 3 & 29 & 2 & 17 & \multirow{3}{*}{68} & 7.870 & 8.944 & 0.170 & BAIK \\
\hline & P. BURLNG & 3 & 31 & 2 & 16 & & 16.505 & 8.357 & 0.149 & BAIK \\
\hline & P.LANGGAR & 3 & 32 & 2 & 15 & & 16.319 & 8.329 & 0.145 & BAIK \\
\hline \multirow{3}{*}{ Sidodadi } & DRCIPTO & 3 & 30 & 2 & 16 & \multirow{3}{*}{68} & 7.943 & 8.804 & 0.141 & BAIK \\
\hline & $\begin{array}{c}\text { SIDODADI } \\
\text { TIMUR }\end{array}$ & 3 & 34 & 2 & 14 & & 17.153 & 9.115 & 0.133 & BAIK \\
\hline & $\begin{array}{c}\text { SIDODADI } \\
\text { BARAT }\end{array}$ & 3 & 33 & 2 & 15 & & 17.467 & 9.221 & 0.140 & BAIK \\
\hline \multirow{3}{*}{ Majapahit } & DRCIPTO & 3 & 31 & 2 & 16 & \multirow{3}{*}{68} & 8.252 & 9.284 & 0.200 & BAIK \\
\hline & MAJAPAHIT & 3 & 33 & 2 & 15 & & 8.299 & 9.492 & 0.205 & BAIK \\
\hline & AYANI & 3 & 30 & 2 & 16 & & 8.009 & 9.151 & 0.180 & BAIK \\
\hline
\end{tabular}

Sumber : hasil analisis, 2019

Berdasarkan perhitungan simulasi 1 hingga 5. Secara keseluruhan derajat kejenuhan berlangsung dengan baik. Dan untuk panjang antrian di sepanjang jalan Dr Cipto mengalami sedikit kenaikan di awal simulasi dan penurunan antrean di akhir simulasi. Sebagai contoh panjang antrian di jalan Dr Cipto 3 pada sinpang majapahit di simulasi ke 4 mengalami kenaikan panjang antrian sepanjang, 11,38 m. namun pada akhir simulasi yaitu simulasi ke 5. Panjang antrian berubah menjadi $8,25 \mathrm{~m}$. hal ini dapat diatasi karena pengecilan waktu siklus. Diperlukan waktu siklus yang tepat agar tidak menjadikan derajat kejenuhan dan panjang antrian semakin tinggi. Dalam perhitungan ini simulasi ke 5 memiliki waktu siklus dan waktu hijau terbaik di antara simulasi 1 hingga simulasi 4. Dalam perencanaan ini, digunakan kecepatan rata-rata existing sebesar $40 \mathrm{~km} / \mathrm{jam}$. Kecepatan rencana ini dipilih karena cukup memenuhi kecepatan maksimum kendaraan dalam kota sesuai standar yang berlaku saat ini. Kendaraan dengan kecepatan yang lambat akan menghasilkan waktu offset yang panjang sehingga kendaraan terakhir dalam platoon masih memiliki kesempatan untuk mendapatkan waktu hijau dan tidak perlu untuk menunggu waktu hijau dalam satu siklus lagi. Waktu tempuh dari simpang Titik 0 menuju simpang majapahit adalah :

$t=\frac{\operatorname{Jarak}(S)}{\operatorname{Kecepatan}(v)}=\frac{2,8(\mathrm{~km})}{40\left(\frac{\mathrm{km}}{\mathrm{jam}}\right)}=0,07 \mathrm{jam}=4,2$ menit $=252$ detik

Dari beberapa data yang di tampilkan, berikut merpakan kesimpulan data yang disajikan dalam tabel berikut:

Data rekap jalan Dr Cipto kinerja Panjang Antrian, Waktu Siklus, Derajat Kejenuhan

\begin{tabular}{|c|c|c|c|}
\hline & \multicolumn{3}{|c|}{ Kineria } \\
\hline Jalan & Pamiang Antrian $(\mathrm{m})$ & Waktus Skikus (detik) & Derajat Kejenuhan \\
\hline DRCipto 1 Simpang Kartimi & 7.870 & 068 & $68 \quad 0.170$ \\
\hline DRC"ipto 2 Simpang Sidodadi & 7.943 & 68 & 0.141 \\
\hline DRCipto 3 Simpang Majapahit & 8.252 & 68 & 0.201 \\
\hline
\end{tabular}

Berdasarkan tabel berikut dapat disimpulkan bahwa jalan Dr Cipto 3 di Simpang Majapahit memiliki panjang antrian, dan derajat kejanuhan yang cukup tinggi. Dengan data panjang antrian 8,252 $m$ dan derajat kejenuhan 0,2 .

\section{KESIMPULAN}

\subsection{Kesimpulan}

Terdapat beberapa hal yang dapat disimpulkan dari studi penerapan serta hasil analisis yang sudah dilakukan adalah sebagai berikut :

1. Setelah dilakukan simulasi Panjang antrian tertinggi terjadi di jalan Dr Cipto 3 di Simpang Majapahit 
sepanjang 8,252 $\mathrm{m}$ dengan waktu siklus 68 detik dan waktu Siklus 0,2.

2. Koordinasi antar simpang menghasilkan waktu offset (waktu tempuh antar 4 simpang dengan kecepatan rencana $40 \mathrm{~km} / \mathrm{jam}$ ) antar 4 simpang yaitu 252 detik.

\subsection{Saran}

Dari kesimpulan tersebut, terdapat beberapa saran yang dapat usulkan, yaitu : 1. Perlunya pengecekan derajat kejenuhan dan panjang antrian tiap bulanya dan perlunya pemasangan ATCS (Area Traffic Control System) di sepanjang jalan Dr Cipto.

2. Penelitian ini dapat dilanjutkan dan diterapkan kembali pada simpangsimpang yang lain supaya mengurangi angka kemacetan di Kota Semarang

3. Seiring berjalannya waktu, jumlah kendaraan akan terus bertambah sedngkan kapasitas jalan tidak mungkin lagi untuk ditambah dan perubahan geometrik pun sulit untuk dilakukan, maka dari itu perlu kebijakan serius dan tegas dari pemerintah untuk menekan pertambahan jumlah kendaraan.

\section{DAFTAR PUSTAKA}

Asanan, Ali. 2014. Rekayasa Lalu Lintas Dan Persimpangan Jalan. Diakses dari http://slideshare.net/aliasnan/rekayas a-lalu-lintas-dan-persimpangan-jalan

Direktur Jenderal Perhubungan Darat. 1996. Pedoman Teknis Pengaturan Lalu Lintas di Persimpangan Berdiri Sendiri dengan Alat Pemberi Isyarat Lalu Lintas. Departemen Perhubungan.
Kementerian Pekerjaan Umum. 2014. Kapasitas Simpang Apill: Kementrian Pekerjaan Umum.

Kristanta. 2013. Aanalisis Kinerja Pelayanan Umum Di Kabupaten Ponorogo. Skripsi UMS. Diakses Dari http://v2eprints.ums.ac.id/archive/etd /24325/

Meditra, Tody. 2010. kinerja bidang lalu lintasdinas perhubungan kota semarang : Universitas Sebelas Maret Surakarta.

Republik Indonesia Derecktorat Jenderal Bina Marga Direktorat Bina Jalan Kota (BINKOT). 1997. Manual Kapasitas Jalan Indonesia (MKJI), Direktorat Bina Jalan Kota.

Sunyoto,Descraredo Henky. 2018. Studi Penerapan Area Traffic Control System (ATCS) Di Beberapa Simpang Kota Semarang. Skripsi Unika Soegijapratana: Semarang. Diakses Dari http://repository.unika.ac.id/18505/

Susanti, Erna.2014. Analisa Arus lalu Lintas Menerus (Through Traffic) Di Kota Surakarta dari Arah Barat. Skripsi UMS. Diakses dari http://v2.eprints.ums.ac.id/archive/etd /32055/1/

Tyas, Yanuar Isti Cahyani. 2016. Optimalisasi Kinerja Simpang 3 Bersinyal Pamungkas Dan Pengaruhnya terhadap Angkutan Umum. Skripsi UII ( Universitas Islam Indonesia). Diakses Dari http://dspace.uii.ac.id/handle/123456 789/111/ 